\title{
Operational Aesthetics
}

\section{Lucy Orta}

\section{Introduction}

This chapter coincides with the twenty years of my practice as a contemporary artist, so it seems fitting that I cover the evolution of my work after having left the Parisian fashion industry, through founding Studio Orta with my partner and husband, Jorge, in 1991, and its development into a large team of interdisciplinary artists and theorists committed to creating and communicating with an artistic format that is both representational and operational, Operational Aesthetics (Aesthetic en Fonctionement). ${ }^{1}$

Although Jorge and I both have solo practices - Jorge throughout the difficult dictatorial years in Argentina between 1970 and 1982 and in Paris from 1983, and my own since 1992-we have always worked collaboratively, provoked by the same key questions:

How can art practice pave a new critical role, faced with the growing problems in this world?

How can it erase the contradictions between formal aesthetics and social function?

How can works of art empower and nurture constructive dialogue?

What contribution can we as artists make to human and environmental sustainability?

Our artwork is widely exhibited in galleries and museums worldwide, but these public presentations represent just a fraction of our multifaceted studio production and 
communication processes. We strive to create artistic forms that 'speak' different visual languages within varying contexts and for diverse audiences, be it within the confines of the white cube or the intimacy of the home, the playground of the public space or interacting with the wider community.

We employ a huge diversity of media - from drawing, print, embroidery and couture, to welding, carpentry, silkscreen printing, installation, glass blowing, architecture, intervention, light projections, sound, performance, photography and video-but we are conscious that the vast array of resulting artefacts cannot just represent our complex and changing epoch. On the contrary, they should be active within people's lives, reactive to and act as trigger catalysts for solutions for society at large.

\section{I: Portable architecture}

Just as I was beginning to make a successful career in the Parisian couture houses, the first Gulf War exploded, followed by stock market crashes and the consequences of the devastating economic recession. My encounter with Jorge in Paris in 1991 triggered my gradual transition away from fashion design into contemporary art, inspired by his work and an increasing need to become more socially active and to find a new creative medium with which to express the effects of the social instability around me.

The first visual manifestation of my work was Refuge Wear (1992-98), a response to dual global crises: the humanitarian aid appeals for shelter and clothing for the Kurd refugees fleeing the war zones, and the increasing numbers of homeless people on the streets of Paris. The first sculpture I realised was Habitent (1992), a portable habitat designed for minimum personal comfort and urgent mobility for nomadic populations. Habit implies a garment for meditation and spiritual refuge, the inhabitant suggesting a human presence as an occupant for the dwelling. The aluminium coated one-person tent with telescopic armatures transforms in a matter of seconds into a wind-waterproof poncho.

Using my design expertise, I went on to explore further individual convertible shelters. The forms allow for the minimum vital space around the body and the materials used 


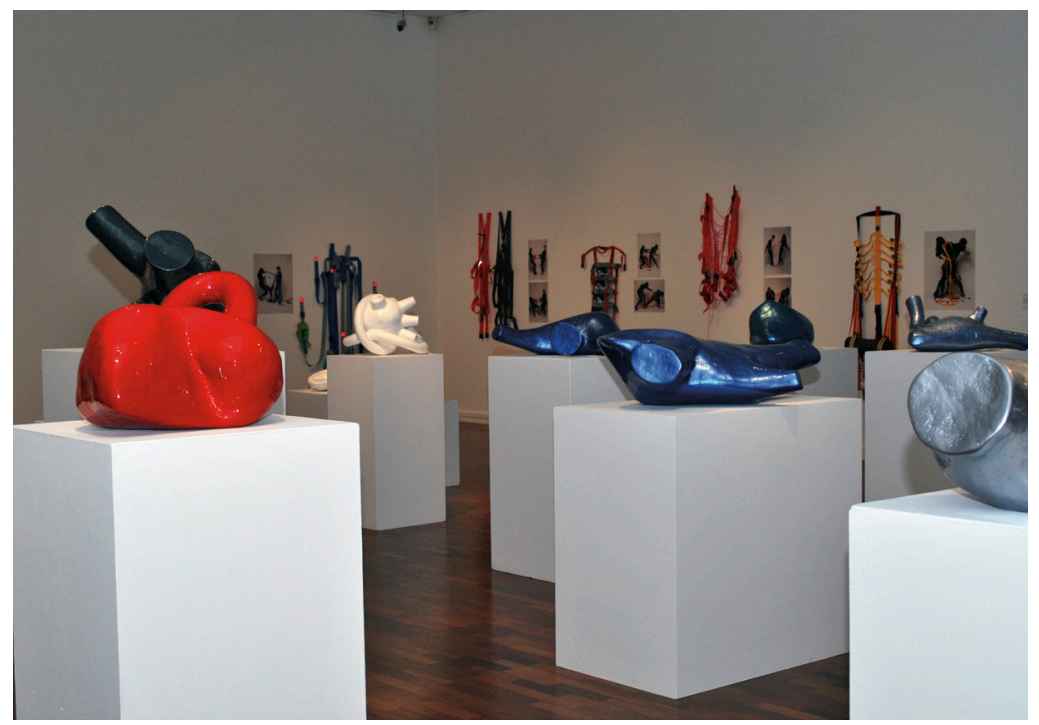

$1 \quad$ Lucy and Jorge Orta

Life Nexus - The Gift, 2002/2010

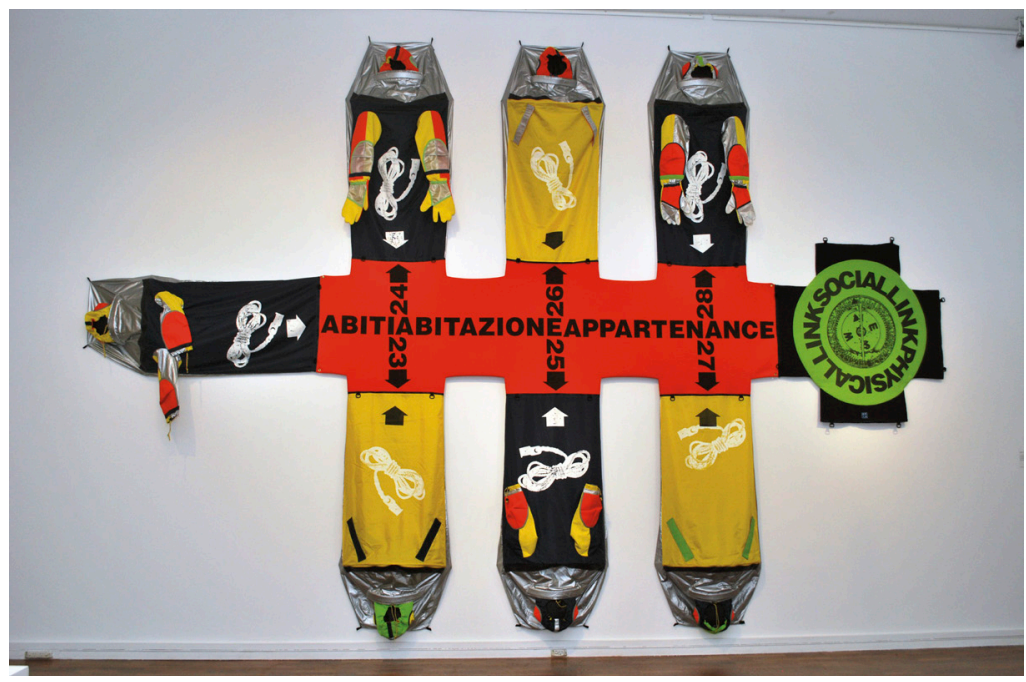

2 Lucy and Jorge Orta

Nexus Architecture - Harness, 2007/2010 
are chosen for their 'comfort-seeking' properties, further extending the metaphorical aspect of each artwork. For example, a combination of microporous Rip Stop with a PUcoated polyamide protects against abrasion during mobility, but at the same time takes into account basic physical needs. The Habit-Bivouacs (1993-94) incorporate carbon armatures that raise the fabric above the chest to eliminate the effects of claustrophobia. These supporting structures are lightweight and telescopic, evoking pop-up architecture. Refuge Wear often has arm or hood appendages and converts into backpacks, or pockets containing both functional and symbolic objects. The transformation from shelter to clothing and vice versa is fundamental to the concept of freedom of movement, free will or choice, new relationships and new cultural exchanges, the homo mobilis.

\section{Workshops}

In 1993 I was invited to exhibit Refuge Wear at the Salvation Army shelter in Paris (Cité de Refuge). The show 'Art Social Function!' marked the sixtieth anniversary of the hostel designed by Le Corbusier. On one of the Refuge Wear bivouacs suspended in the entrance hall of the hostel was silkscreen printed text: 'Living without a shelter for prolonged periods rapidly deteriorates physical and moral health. The lack of adequate sleep increases stress, weakens the immune system and accelerates the loss of identity and de-socialisation.'

The artworks became the focal point for discussions with the residents, and so we created a drop-in workshop with the hostel staff to channel their feelings through dialogue, drawing and poetry. This led naturally to a series of Refuge Wear 'trials', which resulted in confessions about residents' homeless experiences and suggestions on how their precarious conditions could be ameliorated with numerous stopgap solutions. These emotional encounters marked a change in my studio practice as it became apparent that workshops were more than just an artist offering a skill. A highly rewarding creative exchange and partnership could be nurtured between participants and artist-co-creation. In the words of the director of the Salvation Army: 'I am convinced today that in the launching of socialisation, it is difficult to have access and 
go towards art and culture, they must come towards our public. Culture must be included in the world of exclusion.'2

\section{Interventions}

As urban theorist and philosopher Paul Virilio has often pointed out, the industrialisation of vision in the modern world has led to the over dominance of images within our society. To be homeless in a media culture such as ours is therefore to be rendered invisible, to melt literally into the margins and framework of the city. 'Out of sight out of mind' is an aphorism that has a more pertinent meaning to those disenfranchised members of society who fall through this gap. Jorge and I staged Refuge Wear city appearances - Interventions - to challenge that act of social disappearance and to render the invisible visible once more. Peripheral urban spaces, such as squats, railway stations, housing projects, bridges and subways, were chosen as arenas for simultaneous happenings that were recorded for French and British television. ${ }^{3}$ The Refuge Wear sculptures and the subsequent interventions in the urban space acted as warnings, alarms or distress whistles to signal certain aspects of reality that the media ignore or simplify, before they evacuate it completely.

\section{Collective}

Meeting Virilio in 1994 was a significant turning point in my practice. His research at the time focused on the breakdown of the family unit and the need to reconstruct the social link: 'The precarious nature of society is no-longer that of the unemployed or the abandoned, but of that of individuals socially alone.' ${ }^{4}$ The Refuge Wear and Survival Kits I had been creating were concerned with the notion of individual survival, but it became more apparent that I should be investigating the role of the individual within a community structure - the collective body.

Virilio's philosophy and social criticism encouraged me to explore new structures and processes for stimulating dialogue and interaction. I went on to create Collective Wear Body Architecture (1994-99), larger-scale domes and collective tent-like sculptures that sought to promote the opposite effect of the individual isolated units in the Refuge Wear series. The 
surface skins of these Body Architecture enclosures have many facets and appendages - demi-bodies - that represent individuals within a community and at the same time evoke the complexities of sharing space. The first in the series was Body Architecture × 4 (1994), exhibited at the Musée d'Art Moderne in Paris, installed alongside Refuge Wear. In the study Body Architecture Soweto (1997) the external membrane of the tent-structure is covered in second-hand clothes, purchased from the community markets in Soweto townships in South Africa during a research trip for a commission for the 2 nd Johannesburg Biennale.

\section{Communities}

Connector Body Architecture (2001-06) marks the transition from the Body Architecture studies and expands the metaphor of community interaction. Jorge and I created Dome Foyer (2001), a structure taking the form of a meeting hub, a central axis onto which six to eight bivouac pod units could be zippered on and off. We presented the Connector Mobile Village (2002) at the Lothringer 13 gallery in Munich, Germany. The same pods were docked into a connective channel in the form of linear modules, each with a numbered docking bay. The green node allowed different structural configurations and the open-ended possibility to create larger connector networks, replicating the rhizome-like fabric of our community interactions.

The Connector project became a fascinating subject for workshops, which we ran simultaneously in different cities and community groups across the world, from Mexico to Japan, from France to Florida. During the workshops, ideas to diversify the habitable pods were developed into prototypes, allowing for huge variety of individual units among the expanding population of this mobile village.

The Connector Guardian Angel was created together with ex-voto painters in the Zocalo district of Mexico City, depicting scenes they witness daily in the streets. This segment was commissioned for the annual Historical Festival, which aimed to bring culture to the heart of the Mexico City, where crime and poverty is at its highest density.

The Makrolab Connectors, anoraks-cum-sleeping bags, 
were a wearable environmental manifesto imagined during a residency on Makrolab - an autonomous travelling research station that relied entirely on sustainable energies, positioned on the environmental reserve Rottnest Island, off the coast of Western Australia. The anoraks are prototypes for crew uniforms, fashioned with thermochromic textiles, silkscreen-printed with an environmental charter. They have an integrated portable solar panel designed to power a mobile phone or laptop. The rucksacks unzip from the jacket and can either attach to walls of the laboratory, doubling up as storage space, or connect back onto the metaphoric Connector Village sculpture.

Created during workshops with fashion students in the French town of Cholet, the Cholet Connector, with its gestural extending arms, is one of the most pertinent responses to the notion of interconnectivity, extending out to others to feel part of a larger connective social structure: detachable, mobile, yet inextricably connected.

\section{Mobility}

Jorge and I also develop itinerant vehicle structures, Mobile Intervention Units - MIU (2002, on-going), and we're not alone in addressing the needs of humanity with these kinds of mobile dwelling spaces. A range of artists have been working on the 'containerisation' of living space, exploring the overlaps between architecture and urban planning to realise sculpture as fully self-sufficient and mobile social spaces. Joep van Lieshout's AVL Projects are modular living units; Krzysztof Wodiczko Homeless Vehicles provide marginalised groups with a 'street tool' to transport the basic necessities of a survival economy. Dré Wappenaar's tents function as dens, attracting a diverse range of people to gather inside and engage with a message of awareness. Andrea Zittel, Alicia Framis, Tobias Rehberger, Jorge Pardo, N55, Plamen Dejanov and Swetlana Heger, to name but a few, are all artists whose work is grounded in the social dimensions of collective action and the understanding of itinerant communities.

Like the goals of the Connector Mobile Village, our MIU are itinerant civic vehicles that address important issues relating to presence and speech in delivering an itinerant platform for 
communities who cannot reach centres of power. Two of our most pertinent works, reconditioned Red Cross ambulances, were positioned in front of the city hall in Trieste, Italy, for the G8 Environment Summit in 2002. The visual imagery and graphic signifiers applied to their façades quite explicitly referenced the combined social and environmental subjects needing urgent attention: the foot-and-mouth epidemic, waste food mountains, water shortage, extreme poverty and much more.

Dwelling $X$ (2004) evolved from a series of co-creation workshops on the theme of personal and shared space held with a local youth group in the city of Nottingham. Responding through drawing and model making, a series of architectural floor plans became a focus for the motifs silkscreened onto an inflatable membrane, alongside the silhouettes of each participant. The balloon-like membrane, synonymous with the womb, becomes the extension of a huge mesh heart, an architectural proposal combining two distinct evocative spaces. Nestling on the lorry in the centre of the busy market square, its diaphanous form acts as a mobile beacon for the new contemporary art museum to be built in the city; at the same time, it provides a public platform for interrogating and engaging with new forms of public and participative art.

\section{Nexus}

When I first began making work that physically connected people, Virilo commented: 'Each individual keeps an eye on, and protects, the other. One individual's life depends on the life of the other. In Lucy's work, the warmth of one gives warmth to the other. The physical link weaves a social link.' 5

The body of work Nexus Architecture (1994-2002) (Figures $1 \& 2)$ is regarded as an emblem of my practice. Nexus means link or bond and the symbolic content is more important than functional. In this work clothing becomes the medium through which social links and bonds are made manifest, both literally and metaphorically. The links of zippers and channels, while enhancing the uniformity of the workers' overalls, create androgynous shapes that defy classification by the usual social markers, and attempt to give form to 
the social, not the individual body. As fashion sociologist Dr Joanne Entwistle states: 'Instead of differences, we are offered a powerful vision of possible, momentary collectives or networks of being, whose connections are rendered visible and visceral in time and space.' 6

The connecting elements are direct embodiments of a social link, a 'social sculpture' worn in public spaces and used for ephemeral interventions in contextual locations. During the interventions performers and passers-by become physically involved in the construction of each scenario, which is filmed and photographed: climbing into the suits, zipping the Nexus, walking, moving in unison, creating an unusual closeness, questioning interdependence by being part of it, physical and visceral. The recurring public manifestations of the work create a poetic series of interrelated segments regardless of religion, sex, age or social status.

The surface fabric of each Nexus suit is adapted to the context of each public intervention, and is silk-screen printed with inscriptions relating to current affairs. A segment of sixteen suits created for the Venice Biennale (1995) were inscribed with newspaper headlines reporting the genocide in Rwanda and worn by architecture students throughout the biennale opening. Participating in the Global March Against Child Labour (1998), teenagers from an orphanage I had worked with communicated the UN Declaration for Children's Rights as they marched across France.

For the 2nd Johannesburg Biennale commission (1999) I chose to use traditional textiles from the colourful Dutch wax prints and African Kangas purchased in South Africa, and this formed the basis for a community workshop for migrant female labourers from a local city shelter. The women were inexperienced in sewing and were given a demonstration on the basic processes of cutting and manufacturing so that each woman could gain a skill. They selected their preferred graphic designs and each cut and stitched a suit. The result was a stunning patchwork series of Nexus links, and a moving intervention of solidarity in the city of Johannesburg as we created a magnificent human chain chanting anti-apartheid freedom songs. At the end of the workshop the women adopted the suits for personal use including the social link, 
perhaps in their minds the most important feature of the design. In Johannesburg, the Nexus Architecture experience produced the most beautiful suits, but more importantly it was a process of bringing forth the possibility of solidarity in a fractured environment where solidarity can be difficult to muster and maintain.

Nexus Architecture later evolved from the linear configuration to a crisscross of connections evocative of the molecular structure of atoms. Several hundred suits existed in this series and the full installation carried an extremely powerful message. This included a gathering of over fifty performers and passers-by in front of Cologne Cathedral to mark the opening of the exhibition 'Unwearable' at the Angewandte Kunst Museum (2000). In the city of Cholet, a city devastated by closures of some children's clothing manufacturing plants, we staged a public intervention to coincide with a survey exhibition at the museum of fine art. Over one hundred local children and their parents participated in workshops led by the museum to learn about the UN Declaration of Children's Rights (2002).

\section{Survival}

The Life Guard series (2002, on-going) is based on an adaptation of the worker's overall block. It is used as a starting point for a multitude of different assemblages to create both objectbased and performative detournements. The extension of the garment incorporates Red Cross army-surplus articles, camp beds, tarpaulins with their rigid frames and stretchers and bed linens with protruding handles. The first-aid stretchers transform into connected figures, which are both supportive structures for the wearer and transportable aid devices for the bearer. Camp-bed mattresses detach from their frames and morph into sleeping bags, rucksacks convert to multiple habitats and linen tarpaulins mutate into collective harnesses. Even rubber dinghies deploy to create wearable life rafts, and lifejackets pop out of canvas courier bags.

Urban Life Guard formed the central discourse of my exhibition, The Curve, at the Barbican Art Gallery London (2005). Comprising 23 suspended stretcher beds incorporating over sixty figures, I reflected on the notion of assistance and 
the assisted, whereby the body is not only understood as the measure of one's capacity to overcome ordeals or support for others in distress, but also as a fragile structure to be preserved.

\section{Portable Protest}

Portable Protest (2004-08) is a response to the second Iraq invasion in 2004, and builds upon work that Jorge and I have been developing since the outbreak of the 1991 Gulf War. The work was commissioned by the Victoria and Albert Museum's late night performance evenings to be held on 25 June 2004, just five days before the hand-over of sovereignty to the Iraqi government and the start of the withdrawal of US and allied forces. Together with 50 volunteer performers, we staged a passive protest for peace wearing gold-printed combat suits. For over two hours we silently meditated the future fate of Iraq and its citizens amid the tombs, sepulchres and war trophies from historical battles and combats.

Eyewitness accounts conducted by Dr Jonathan Holmes for the verbatim play Fallujah, on which we collaborated and which was performed in 2007 , recount the desperation of medical staff, the horrors of combat and the voices of the citizens from inside the siege of this Iraqi city. We became even more anxious to reveal the truth behind this political manipulation and media censorship through our work, so Portable Protest and new sculptural works were used as the backdrop for a seven-week performance in London. The independent NGO project 'Iraq Body Count' estimated that over thirty-four thousand civilians were killed in Iraq in 2006 alone, 1.8 million were driven from their homes and over two million fled to other countries. What happens to the people whose livelihoods, homes and daily routines are permanently and irrevocably changed through the violation of their basic human rights in the name of Western democracy?

In keeping with the flexibility of our work, Portable Protest also toured in the form of a static installation to the 2006 Gwangju Biennale in South Korea, a city famous for student protests against the dictatorial regime and now a symbol of the country's pro-democracy resistance-a movement with special poignancy in light of the political situation that still divides the peninsula. 
II

In this section I focus on four areas of collaborative research, marking the shift away from the body to the global altruistic themes of human rights in the project Antarctica, or food and water scarcity explored in the themes of $70 \times 7$ The Meal and OrtaWater, and the most recent body of work, Amazonia, which interrogates the importance of safeguarding our natural resources.

\section{HortiRecycling}

HortiRecycling (1997-99) points a finger at food waste in European cities, yet it is also a reflection on the inequalities of food distribution globally. The works begins its life as All in One Basket (1997), an installation of artworks centred around an open-air buffet in Les Halles, Paris, produced from over three hundred kilograms of discarded fruit that we had gleaned from the local markets. We enlisted the help of the famous chef-pâtissier Stohrer, who helped prepare and cook the produce into a variety of gourmet dishes, thereby 're-civilising' this so-called abandoned food. Samples of jam, jellies and puddings were available in small taster bowls for free, and in the adjacent Galerie Saint-Eustache we installed a collection of artefacts constructed from wooden fruit crates containing our homemade preserves, alongside photographs of mounds of discarded market produce. Visitors could buy souvenir editions of our bottled and labelled preserves or listen to personal stories from the community of gleaners at the weekly markets in the form of audio recordings from the Walkmans integrated in conservation unit trolley sculptures. During the course of the opening, thousands of members of the art community, shoppers, children, tramps and students stopped by to discuss both art and food issues.

Two years later we staged a second phase of HortiRecycling (1999) in Vienna, thanks to a commission for the Weiner Secession. Taking advantage of the proximity of the local fruit and vegetable Naschmarkt opposite the gallery, the energetic Secession curators helped us carry on the legacy of the Viennese manifesto, 'to every age its art and to art its freedom'.7 After reflecting on the cycle of food recycling, we perfected our methods of collection, processing and distribution to provide 
market vendors with brightly coloured collect units. This enabled a rapid and more hygienic gathering of produce, instead of collecting it directly off the street. At the end of each market day we fetched the bags using our specially fabricated processing units (mobile kitchens) and pulley systems installed inside the gallery. Thanks to these functional sculptures with fully integrated sinks, hotplates and freezers, we were able to clean, cook, bottle and freeze the ripe food on the spot, thereby putting into place a novelty recycling system with the potential to be adopted one day.

\section{$70 \times 7$}

Following the success of the social gatherings and the passionate discussions ensuing from the open-air buffets, we developed a third phase of these gastronomic works in the form of an unfolding series of meal performances: $70 \times 7$ The Meal (2000, ongoing). This participative body of work is inspired by Padre Rafael Garcia Herreros (Colombia, 1909-1992), who initiated a series of benefit banquets called El Minuto de Dios to fundraise for a major urban social development programme that would radically transform one of the most abandoned zones in the city of Bogotá. The dinners were so successful that they raised enough funds to build El Minuto de Dios, a whole district complete with community schools, homes and gardens, a theatre, a contemporary art museum, small factories and a university.

The symbol $70 \times 7$ has its roots in the biblical signification meaning Ad Infinitum (Lc. 17.4) that serves as a pretext to bringing about multiple encounters between guests, who are invited to dine in surprising installations and participate in an 'endless' banquet. Seven guests invite seven others, and so on, so the act of creating the meal happens through the chain-reaction of human interaction. We are merely triggers or enablers in a process.

$70 \times 7$ The Meal series is an invisible artwork taking the form of our most cherished rituals and mimicking the essential human needs to eat and to unite. Only small signals, such as the limited edition Limoges porcelain plates and hand-printed tablecloth created for each event, leave a trace that something unusual has brought these guests together. 
We hope that these clues remain discreet so as not to incite a 'fear of art' and to allow the catalyst encounters to blossom naturally. Setting the meals in an urban space is a return to the need for spontaneous general assemblies around specific subjects, bringing people to concert, to reconcile, to reflect together, with the potentiality of an artwork that is active in the heart of a community. The invisibility of the art renders this tool more effective by erasing the fear of 'not belonging'.

One of the most successful of these community gatherings was $70 \times 7$ The Meal, act IV (2000). This was staged in Dieuze, France, a rural town of three thousand inhabitants with a culturally divided population of air force servicemen, miners, farmers, immigrants and unemployed. Commissioned by the local youth centre and in collaboration with seven local associate groups, we contacted every inhabitant in the town using word of mouth, press, radio and door-to-door mailings to encourage the largest possible participation. We closed the main street and installed a half-kilometre table, adorned with a red runner. Special limited-edition Royal Limoges plates were inscribed with the hopes and wishes of the inhabitants, which had been collected during the 18 -month period prior to the event. Its success was marked by a tremendous turnoutover half the population and over seven hundred and fifty porcelain dining plates sold on the day!

What started out as an intimate dinner for seven members of the farming community at the Kunstraum in Innsbruck (2000) has evolved through 32 meals installations across the world with thousands of people involved in the act of creation. Our fiftieth act, covering several miles of streets starting from Tate Modern and running across the Millennium Bridge to Guildhall, the historical centre of London, hasn't been realised yet, but from past experience, and with our $70 \times 7$ multiplication strategy, we know it is possible to unite several thousand people around the same table. Each act of the meal has served as a forum for proposing new political, educational, social and environmental debate, as well as fund-raising for important social or environmental causes. Nobody can change the world with a meal, but each meal, and its infinite accumulations, has the potential to change the world, even if it's in a small way. 


\section{Ortawater}

This body of work began its life as an exhibition proposal titled 'Drink Water', commissioned by the Fondazione Bevilacqua La Masa for the Venice Biennale (2005), which toured to the Museum Boijmans Van Beuningen Rotterdam (2006). The initial premise was Venice, a city built on water and dependant on it for its livelihood, but more importantly our research process and resulting artefacts were designed to focus our attention on the general scarcity of water, and the issues surrounding the privatisation and corporate control affecting access to clean water for all.

Starting from an analysis of this crucial issue through visual and textual research, together with international interdisciplinary workshops and seminars, we collectively brainstormed ideas for sculptures, large-scale installations, public artworks and pilot projects that would both evoke the cycle of water and prompt ideas to design and implement clean-water projects for communities in need. Catalogued in sketchbook format, the resulting drawings aimed to pose questions through the surprising juxtaposition of hand-made structures, and the incorporation of functional found objects referencing a wide range of water issues. We reflected on cycles of water from the source to the pump, from the purification to the packaging and distribution. We created small MIU urban vehicles, such as the Ape Piaggio, low-cost manpowered distribution structures and water reservoirs, mobile water fountains, Venetian-style transport trolleys, vitrines, boats and water Life Guard artefacts, which oscillate between the metaphoric and the functional/operational.

\section{Fluvial Intervention Unit (FIU)}

The hundreds of low-cost water purification devices we discovered during our research were of particular significance. We went as far as incorporating a fully-functioning filtration system into the FIU Pumpstation sculpture, which pumped the filthy Canal Grande into the immaculate Venetian gallery, through a filter circuit of connecting pipes in the artworks directly to the brass taps inserted in each object, to simply demonstrate, through the act of drinking, that the filthiest water in Europe is drinkable and available to taste for the thousands 
of visitors to the exhibitions. In Rotterdam we pumped the Emmasingel Canal through the rear door of the museum in a network of pipes and bridges that wound their way through the historical fine art galleries, among the Van Eycks and Breugels, into the exhibition space. Once again, the general public could just turn on the taps and take a drink. As the engineer we collaborated with demonstrated, it's not rocket science!

\section{Editions}

One of our dilemmas was how to incite people to drink the filthy canal water and partake emotionally in the experience of the water's transformation. 'If it were in a bottle would it please you more!' 8 We drew on the bottled water product of our market system to create limited edition artwork, OrtaWater (2005-06): clean water, bottled at source from the canals and available for the general public to take away.

Reflecting on 'Operational Aesthetics', our approach as artists is to contribute proactively to the widening of our understanding of the dilemmas ahead, and of course this is impossible to do alone. We conduct interdisciplinary workshops to engage industry partners with students from art, architecture and design schools across Europe; among the participants are graduates from the University of the Arts London, Fabrica Italy, Design Academy Eindhoven, Willem de Kooning Rotterdam, Delft University, Città dell Arte Italy. The Boijmans Van Beuningen Museum workshop conducted throughout the duration of the exhibition was instrumental in establishing a 'Water for Women' think-tank. This was aimed at improving access to clean water in the community of Bwaba in Burkina Faso, which has no running water and only one aquifer, situated 20 kilometres from the village.

\section{Antarctica}

As part of Jorge's project for his representation at the 1995 Venice Biennale, we presented a draft proposal for the Antarctica World Nationality and the proposal for a new Utopia in a project that became know as Antarctic VillageNo Borders (2006-08). This idea focuses on the only unclaimed landmass on earth, Antarctica, which is governed by the Antarctic Treaty signed by twelve countries in 1959. This 
peace treaty was the first Arms Control agreement established during the Cold War, and it declared this sixth continent as a scientific preserve, establishing the freedom for scientific investigation, an environmental protection zone and a ban on all military activity. Antarctica is a unique, peaceful territory to which we can all aspire, and the Antarctic Village represents a place of welcome for those fleeing their countries to escape political and social conflict or environmental catastrophesa physical embodiment of Marshall McLuhan's 'global village'.

In 2006 we began producing a temporary encampment of over fifty dome-shaped dwellings. Reflecting qualities of nomadic shelters and temporary campsites, the Dome Dwelling components were assembled in our studio and hand-stitched together by a traditional tent-maker, with sections of flags from countries around the world together with extensions of clothes and gloves symbolising the multiplicity and diversity of people. The flags and fragments of clothes are silkscreen-printed with motifs proposing a new article for the UN Declaration for Human Rights, Art 13.3 - No Borders. This mobile village is a symbol of the plight of those struggling to gain the freedom of movement.

Thanks to a commission by the End of the World Biennale in Ushuaia in 2007, we were able to embark on an expedition to Antarctica, to found the Antarctic Village. At the end of the Austral summer during the months of February-March, we were physically able to install the village in Antarctica, travelling from Buenos Aires aboard the Hercules KC130 flight on an incredible journey. Aided by the logistical crew and scientists stationed at the Marambio Antarctic Base, the ephemeral installation of the first Antarctic Village was finally realised in four locations across the continent after twelve years of research and development.

On our return to Europe, we exhibited the dwellings in an important touring survey show at the Hangar Biccoca spazio d'arte in Milan, Italy, and the Galleria Continua Le Moulin in Paris, and were given the opportunity to create many more artworks in the Antarctica series.

Drop Parachutes and Life Line

Drop Parachutes (2008, ongoing) is an extension of the 
Survival Kits (1995). The pieces resemble mini drop-parachutes using fragments of the textiles left over from the domes. As in many other works, we find an explicit reference to the tools and objects of emergency rescue missions. In this case, the model is the kind of parachute utilised by humanitarian expeditions to rapidly distribute vital supplies.

The Life Line (2005, on-going) life jackets refer to both physical-material rescue and symbolically to the spiritual needs of man. Employing materials such as steel, textile, silkscreen print and assemblage, the combination of found utilitarian or personal objects suspended from handcrafted steel frames reference the recovery of a lost social dimension, such as affection or solidarity.

\section{Antarctica World Passport}

No country is complete without its identity document, and so we have imagined the Antarctica World Passport that can be delivered from the Passport Delivery Bureau (2008, ongoing). The bureaux are constructed from the makeshift furniture and supplies we collected along our journeys, and a passport is distributed during special events that aim to raise awareness of issues affecting a freer, international migration.

The 1948 Universal Declaration of Human Rights, article 13, currently states that the inherent dignity of every member of the human race and their equal and inalienable rights constitute the fundamentals of liberty, justice and peace in the world. However, it does not mention the freedom to move, or to cross borders. If we were to amend this article we could take into consideration the rights of the hundreds of millions of men and women hunted from their native lands by economic ruin, war and political intimidation. The passport serves as a testament to this reflection and here we find a new article to perhaps be adopted one day:

Article 13.3: Everyone has the right to move freely and circulate beyond the state borders to a territory of their choice. No individual should have an inferior status to that of capital, merchandise, communication or pollution that traverse all borders. ${ }^{9}$ 
From the days of the rudimentary analogue data-collection that was employed for the first passport distribution at the Hanger Bicocca, and thanks to an ongoing collaboration with a visual arts program at Massachusetts Institute of Technology, we now have an online database where you can $\log$ in to receive a passport in return for your adherence to the basic principles of human rights. Each Antarctica World Passport distributed is an extra citizen in the database and an extra voice. The first edition of ten thousand passports is printed, and with five thousand distributed so far we have a huge potential to harness a powerful lobbying force.

Inspired by the motto of the End of the World Biennale, 'Here, at the end of the world, is another world possible?', Antarctica is a driving force in this dream.

\section{Amazonia}

Our most recent body of work is Amazonia. This was commissioned by the contemporary art program at the Natural History Museum in London to coincide with the International Year of Biodiversity in 2010. As part of the research leading up to the exhibition we embarked on a second expedition, this time to the Peruvian Amazon. In terms of species diversity the Amazonian rainforests surpass all other forests in the world. A single hectare plot easily contains more than two hundred and fifty tree species and fifteen hundred species of higher plants. The region is home to about 2.5 million species of insects, tens of thousands of plants, and some two thousand birds and mammals. ${ }^{10}$

Organised by Cape Farewell, an artist-run, non-profit body dedicated to communicating the effects of climate change through arts-science collaborations, we travelled with a group of artists and scientists from the Environmental Change Institute (ECI) at Oxford University. This four-week journey took us 4,500 metres up to the Glacier Salcantay, down to 3,500 metres to the Cloud Forest tree line and the science station Wayqecha, down the Andes to 1,500 metres along the Trocha Union, the infamous Inca path through the rainforest, to the Amazon Basin to the tributary river, the Madre de Dios. We navigated a 350 kilometre stretch of Amazon forest, stopping in science stations in the Manú Biosphere Reserve, a UNESCO 
world-heritage site where the highest rate of biodiversity in the world is recorded, to our final departure from Puerto Maldonado. As part of the research, we participated in various scientific data-collection research programs and at the same time recorded this beautiful oasis of diversity through photography, video and sound. The Manú region proved to be an emotional and conceptual starting point for new work that we hoped would restore our focus on the world around us - both its beauty and its imperilled state. On our return to Paris, we began imagining an installation for the exhibition comprising 2-D and 3-D work as well as audio and film.

\section{Drawings}

The drawings Amazonia Expedition Sketchbook are a reflection on our first impressions of and responses to the journey. The works on paper conceptualise the experience of the Amazon and our understanding of the connections between us and the natural environment. We are part of nature and the iconography in the drawings playfully depicts the mutual dependency. But in fact we are more dependent on nature than nature is on us - our presence brings about nature's decline and human decline with it, unless we choose to change and find solutions to these local and global problems by placing us within nature, not outside it.

\section{Sculpture}

Life on our planet is in constant flux. There has been life on earth for 3.5 billion years. Since then there have been five mass extinctions, which caused changes on earth. Extinctions are a natural part of life, but the current rate of loss is about one hundred to a thousand times what it should be. This decline in plants, insects, birds, amphibians, sea-life and other living organisms has become known as the sixth mass extinction, and has one distinguishing characteristic: it is caused by humans. ${ }^{11}$

Using this as a starting point and drawing from the collaborations with researchers in the paleontology department of the Natural History Museum, larger-than-life aluminium sculptures, titled Bone Variation, are modelled on fossilised dinosaur bones from the museum's collection. Despite their 
colourful, iridescent finish, they remain relics of death, a reminder of the many forms of life that have been shaped through evolution, giving us a tangible sense of the contemporary and of times past.

In contrast, the works Collection: Aepyornis, Gallimimus, Allosaurus, Palaeomastodon are delicate sculptures made of fragile porcelain casts from actual specimens in the Natural History Museum collection and imprinted with tiny fragments of life: the egg from the elephant bird Aepyornis, the limb bones from dinosaurs Gallimimus and Allosaurus, and the elephant ancestor Palaeomastodon. Bones are memento mori, reminders of death, but the egg is birth, the start of life. The flowers, butterflies and insects that populate these works point to the cycle of life and the beauty and wealth of our planet. There is an underlying melancholy of the end of time, and the hot breath of extinction. Seeing ourselves as occupying a moment in time, through the reflection of the mirrored surface of the glass plinths, allows us to question our arrogance over nature and the need to work with it rather than against it.

\section{Photography}

The Manú Biosphere Reserve became an important visual focus for the photographic installation Perpetual Amazonia (MLC / one-metre-square / S12 4821.6 W71 24 17.6). Partaking in the scientific research in Manú, we mapped out a one-hectare plot of rainforest and recorded the plant species, the height and diameter of trees that are monitored for the purposes of ecological and climate research. We captured in photography every flower we encountered, enhancing the hidden details such as a stamen, pistil, seed pod, crushed petal or minuscule insect, and continued this photographic methodology during our travels elsewhere, adding to an important database of plant species from around the world. Back in the studio we edited a series of images to which the GPS coordinates in the title and on each photograph refer. We then divided the hectare into ten thousand subplots, each marked with its plot reference and UTM coordinate denoting the exact location of the metre-square plot in the Amazon.

Each photograph is for sale and is accompanied by a 6o-year certificate of moral ownership decreeing the rights 
to protect the plot and its biodiversity, to contribute to the research and at the same time an obligation to pass on the accumulated knowledge to a second generation. This artwork poses many complex questions about ownership, indigenous land rights and the common rights of this natural heritage - we know that land is being expropriated or compulsorily purchased from indigenous populations for exploitation of natural resources and we all know the effects of this daily devastation. In the past 50 years, a third of the world's rainforests have been felled and burned and the UN convention on biological diversity states that in the last eight thousand years about 45 per cent of the earth's original forest cover has disappeared, cleared mostly during the past century! Or as E.O. Wilson so eloquently states: 'Destroying rainforest for economic gain is like burning a Renaissance painting to cook a meal.'

As it was not possible for us to sell the photographs in the Natural History Museum, we proposed a public engagement project for the visitors who were invited to take a Perpetual Amazonia poster and in exchange make a contribution to preserve in perpetuity the metre-square plot it represents and, in doing so, become a steward of the Amazon rainforest. The posters are an extension of the notion of Relational Aesthetics ${ }^{12}$ - they are freely acquired yet engage an active participation; at the same time we prompt the audience to reflect on how we value a hectare of forest, because the loss of nature has a price! With over forty-one thousand visitors to the NHM exhibition, over eight thousand posters were distributed and we raised more than $£ 4$, ooo for research in the Amazon. Even we are surprised with the achievement - this emulates the theory of Operational Aesthetics. Amazonia has marked an important transition in our practice, which is not only aesthetic. It has become a state of mind through which we strive to revive our deep enjoyment of nature and to convey its value to our daily lives and to our survival. 


\section{Notes}

$1 \quad$ N. Bourriaud and G. Williams eds, Lucy Orta (London: Phaidon Press, 2003).

2 P. Ardenne and D. Lebaillif eds, Art Fonction Sociale! (Paris: Cité de Refuge Paris, 1993).

3 Cercle de Minuit, France 2, France, 1996; Dazed \& Confused, Channel 4, United Kingdom, 1998.

4 P. Virilio and L. Orta eds, Refuge Wear (Paris: Editions Jean-Michel Place, 1996).

5 Ibid.

6 J. Entwistle, Refuge Wear and Nexus Architecture, exhibition catalogue (Havana: 9th Havana Biennale, 2006)

7 Phrase carved above the entrance of the Weiner Secession, founded in 1897 by artists Klimt, Moser, Hoffmann, Olbrich, Kurzweil, Wagner and others.

8 Advertising slogan for bottled water in an Italian magazine, 2005.

9 See $<$ http://antarcticaworldpassport.mit.edu $>$.

10 15th Conference of Parties to the UN Framework Convention on Climate Change, Copenhagen, 2009.

11 B. Arends ed., Amazonia, exhibition guide (London: Natural History Museum, 2011).

12 N. Bourriaud, Relational Aesthetics (Dijon: Les presses du réel, 2002). 